\title{
FAKTOR-FAKTOR YANG MEMPENGARUHI BEBAN RANCANGAN (DESIGN LOAD) TERKAIT DENGAN PERHITUNGAN KONSTRUKSI KAPAL- KAPAL NIAGA BERBAHAN BAJA MENURUT REGULASI KLAS
}

\author{
Iswadi Nur \\ Program Studi Teknik Perkapalan, Fakultas Teknik UPN Veteran Jakarta \\ JI. RS Fatmawati, Pondok Labu Jakarta Selatan \\ Iswadi.tp@gmail.com
}

\begin{abstract}
Abstact
The ships construction system must be hold against the inside force of ship although the outside force of ship. The inside force of ship come from the the force of ships lightweight components, and the force ships deadweight components. While the outside force of ship come from the sea water wave and the air flow against the ships hull when the ship is sailing. The influence factors of design load of ships construction calculation such as: the kind of ship, the load force against the ships hull, the length area of ship likes after peak, middle, and fore peak, the area of sea water, the comparison of ships dimension (length/depth), the kind of steel, and the corrosion of steel
\end{abstract}

\section{PENDAHULUAN}

\section{Sistem Gading-Gading Kapal}

Konstruksi kapal adalah kesatuan kulit kapal dengan kesatuan sistem rangka-rangka, dimana untuk sistem gading-gading melintang pada bagian geladak kapal disebut sebagai pelintang geladak dengan balok geladak, pada bagian sisi kapal disebut sebagai gading utama dengan gading besar untuk sistem gading-gading melintang, pada di bagian alas disebut wrang (solid, terbuka, dan kedap), sedangkan untuk sistem gading-gading memanjang kesatuan sistem rangka-rangkanya pada bagian geladak disebut sebagai pelintang geladak degan pembujur, pada bagian sisi besar gading dengan pembujur sisi, pada bagian alas disebut sebagai wrang (solid dan kedap), pembujur alas dalam,dan pembujur alas. Selanjutnya untuk sistem gading-gading kombinasi pada bagian geladak dan alas menggunakan sisrem gading-gading memanjang, dan pada bagian sisi menggunakan sistem gading-gading melintang. Sistem gadinggading tersebut berfungsi sebagai penyangga atau penguat bangunan kapal baik secara melintang maupun memanjang kapal. Secara garis besar sistem sistem sistem gading-gading yang tersebut diatas terbagi dalam beberapa bagian yaitu bagian dasar (bottom) kapal, bagian lambung atau badan kapal (hull), serta bagian bangunan atas (super structure) atau rumah geladak (deck house). Sekat Kapal

Kearah sumbu x (arah memanjang) dan sumbu y (arah melintang) ruangan-ruangan bangunan kapal terdapat sekat (bulkhead). Sekat berfungsi sebagai dinding pemisah antara satu ruangan dengan ruangan lainnya. Sekat memanjang pada umumnya untuk kapal barang terdapat pada badan kapal yaitu pada ceruk buritan dan haluan, serta bangunan atas dan rumah geladak. Pada kapal penumpang baik pada bagian badan, bangunan atas, dan rumah geladak terdapat sekat memanjang berfungsi sebagai pemisah antar ruangan. Pada kapal tambangan dinding pemisah terdapat pada bangunan atas dan rumah geladak. Pada kapal tangki sekat memanjang terdapat pada badan kapal berfungsi sebagai dinding pemisah untuk mengurangi tegangan permukaan muatan cairnya, juga terdapat pada bangunan atas maupun rumah geladak. Pembagian sekat dalam konstruksi bangunan kapal selain berfungsi sebagai dinding pemisah juga berfungsi sebagai cadangan apung apabila kapal mengalami kebocoran di salah satu ruangan. Sekat melintang yang berada pada daerah paling belakang disebut sekat buritan atau sekat ceruk buritan atau sekat tabung buritan (aftpeak bulkhead) selanjutnya pada bagian depan sekat tabung buritan terdapat sekat kamar mesin (apabila 
mesin berada di belakang), pada daerah paling haluan disebut sekat ceruk haluan atau sekat tubrukan (collision bulkhead).Diantara sekat kamar mesin dan sekat tubrukan terdapat beberapa sekat lagi baik untuk kapal penumpang maupun kapal barang.Jadi pembangian jumlahnya sekat melintang tergantung dari panjang kapal, letak kamar mesin, faktor persyaratan kebocoran kapal (floodable length), dan sebagainya.

\section{Geladak Kapal}

Kearah sumbu z (arah vertical) pada bangunan kapal yang membatasi ruangan yang berada di bawah dengan ruangan yang berada diatasnya adalah geladak (deck). Pada bagian lambung kapal terdapat geladak utama (main deck), di atas geladak utama pada bagian buritan kapal terdapat poop deck, di atas poop deck terdapat boat deck, selanjutnya bridge deck, selanjutnya navigation deck, selanjutnya wheel house deck. Sedangkan di bagian paling haluan di atas geladak utama (main deck) adalah geladak akil (forecastle deck). Apabila pada daerah lambung kapal terdapat deck lebih dari satu deck, maka sebutan nomor decknya dimulai dari bagian yang paling bawah.

\section{Alas Kapal}

Dasar ganda (double bottom) merupakan bentuk konstruksi dasar kapal yang mempunyai dasar lebih dari satu yaitu dua. Adanya ruangan ganda dasar ini dapat berfungsi sebagai tempatbermacam-macam tangki untuk kebutuhan operasional kapal seperti tangki bahan bakar (fuel oil tank), tangki minyak lumas (lubricating oil tank), tangki air tawar (fresh water tank), serta tangki ballast (ballast tank). Selain berfungsi sebagai tangki,maka dasar ganda juga berfungsi untuk mempertinggi keselamatan kapal apabila saat berlayar bagian dasar kapal terjadi kerusakkan atau bocor.Tangki kosong (cofferdam) pada dasar ganda adalah ruangan kosong yang berfungsi untuk memisahkan ruang satu dengan ruangan lainnya yang digunakan untuk menyimpan zat cair yang berbeda misalnya memisahkan tangki air tawar dengan tangki bahan bakar, atau memisahkan tangki minyak lumas dengan tangki bahan bakar, dan sebagainya.

\section{Kubu-kubu Kapal}

Pagar atau kubu-kubu (bulkwark) suatu konstruksi di daerah pinggiran deck yang berfungsi melindungi keselamatan jiwa orang yang berada di atas deck yaitu untuk melindungi kemungkinan jatuhnya orang ke luar kapal. Selain itu juga berfungsi untuk menghindari melimpahnya air laut ke dalam deck saat kapal berlayar. Dibawah pelat kubu-kubu terdapat lubang pembebasan adalah suatu lubang yang berada di atas pinggiran deck yang berfungsi untuk membebaskan atau mengalirkan air ke luar kapal yang menggenangi deck akibat limpahan air laut saat berlayar maupun akibat air hujan.

\section{Beban Rancangan}

Sistem konstruksi kapal tersebut di atas harus dapat menahan atau kuat terhadap pengaruh dalam kapal dan pengaruh luar kapal, untuk pengaruh dalam adalah berat kapal kosong dan berat daya angkut, sedangkan untuk pengaruh luar adalah kondisri lautan dan angin pada saat berlayar. Secara teori pengaruh angin tidak terlalu diperhitungkan tetapi pengaruh ombak sangat diperhitungkan. Pengaruh ombak pada saat berlayar gelombang laut dalam perhitungan konstruksi terbagi 2 (dua) kondisi ekstrim yaitu pertama kapal berlayar pada posisi berada satu puncak gelombang (hogging) kamar mesin berada di tengah kapal, kedua kapal berada pada dua puncak gelombang (sagging) kamar mesin berada di buritan. Pada tulisan ini akan dijelaskan beberapa factor-faktor yang akan mempengaruhi perhitungan konstruksi kapal yaitu dalam penentuan beban rancangan (design load) kapal-kapal niaga berbahan baja beradasarkan Biro Klasifikasi Indonesia.Perhitungan beban rancangan tersebut ditentukan secara memanjang kapal dan terbagi menjadi daerah buritan kapal, daerah tengah kapal, dan daerah haluan kapal. Disamping itu perhitungan beban rancangan akan ditentukan oleh beberapa faktor-faktor lainnya seperti jenis kapal, korosi, daerah pelayaran.

\section{FAKTOR-FAKTOR YANG MEMPENGA- RUHI BEBAN RANCANGAN (DESIGN $L O A D)$}

Terdapat beberapa faktor yang akan mempengaruhi perhitungan konstruksi kapal terutama dalam hal kekuatan kapal dan juga dipengaruhi oleh penentuan beban rancangan (design load) kapal-kapal niaga berbahan baja menurut regulasi klas, sebagai berikut.

\section{Pembagian Jenis Kapal}

Jenis-jenis atau macam-macam kapal sangat 
terkait fungsi kapal atau kegunaan kapal,pembagian jenis-jenis kapal terbagi sebagai berikut :

1. Jenis kapal berdasarkan bahan pembuatnya.

2. Jenis kapal berdasarkan alat penggeraknya.

3. Jenis kapal berdasarkan mesin utamanya.

4. Jenis kapal berdasarkan macam barang yang diangkut.

5. Jenis kapal yang dirancang khusus.

6. Jenis kapal berdasarkan deck bangunan atas.

7. Jenis kapal berdasrkan letak posisi tangki di dalam kapal.

Berdasarkan pembagian jenis kapal tersebut di atas terkait dengan perhitungan beban perancangan konstruksi akan memiliki karakteristik yang berbeda.

\section{Tumpuan Beban di Kapal}

Sistem konstruksi kapal-kapal niaga jenisjenis balok tumpuan beban hampir sama dengan bangunan sipil, sehingga perlu disampaikan jenisjenis balok tumpuan yang terdapat di kapal-kapal. Jenis-jenis balok tumpuan tersebut akan terkait dengan pengendalian dan analisis perhitungangayagaya yang bekerja pada balok dan tumpuan, terdapat beberapa macam tumpuan yang dikenal, antara lain;

\section{a. Rol (Penghubung)}

Tumpuan tersebut mampu melawan gaya dalam suatu garis aksi tertentu, seperti gaya tumpuan rol pada garis datar gambar $1 \mathrm{a}$, serta tumpuan pada garis miring yaitu gambar $1 \mathrm{~b}$.

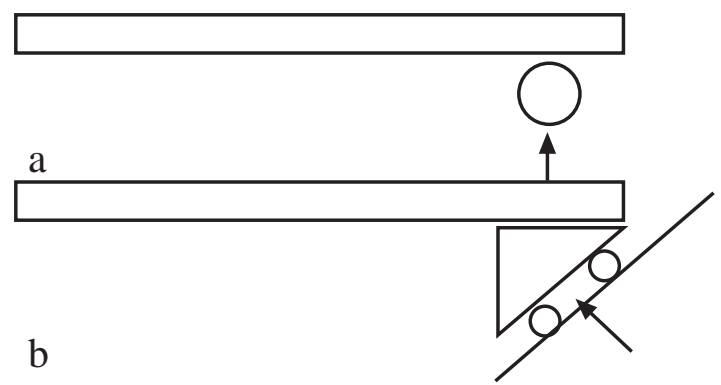

Gambar 1 : Tumpuan Rol

3) Balok Kantilever.

\section{b. Pasak (Pin).}

Tumpuan pasak mampu melawan arah gayadari mana saja, sedangkan untuk sketsa diagramatisnya hanya diekspresikan atau diilustrasikan pada arah vertikal dan horizontal, lihat gambar2.

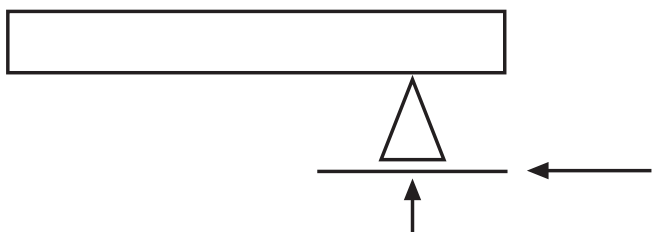

Gambar 2 : Tumpuan Pasak gambar 6.

\section{c. Tumpuan Jepit}

Jenis tumupuan ini mampu melawan gaya pada semua arah serta mampu melawan suatu kopel atau momen, diilustrasikan pada gambar 3 .

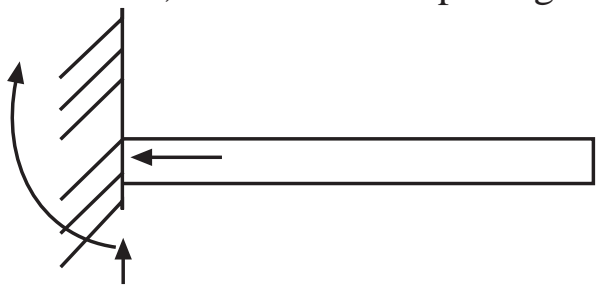

Gambar 3 Tumpuan Jepit

\section{d. Klasifikasi Balok dan Tumpuan.}

1) Balok dengan tumpuan sederhana. Sebilah balok yang ditumpu oleh pasak dan atau rol, seperti gambar 4 a. Balok dengan dua pasak dan gambar $4 \mathrm{~b}$, balok pasak dan rol.

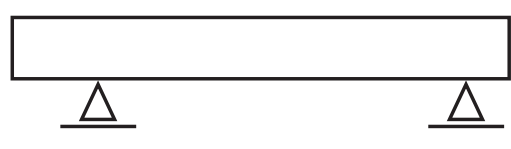

a

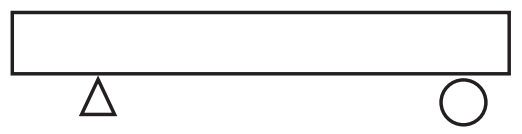

Gambar 4 : Balok tumpuan sederhana

\section{2) Balok Jepit.}

Sebilah balok dengan kedua ujungnya dijepit seperti gambar 5 a, dan salah satu ujungnya dijepit seperti gambar $5 \mathrm{~b}$.
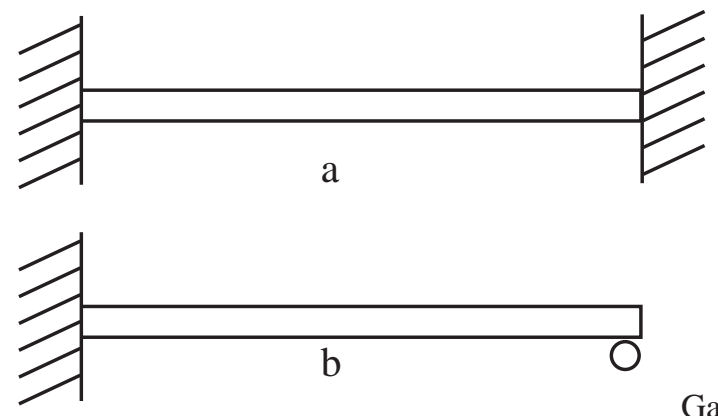

Gambar 5 : Balok

Sebilah balok dengan sebuah ujungnya terjepit dan ujung yang lain bebas sempurna, seperti

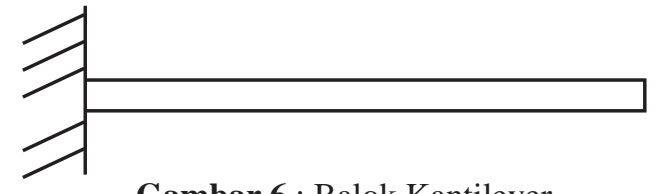

Gambar 6 : Balok Kantilever

\section{4) Balok Tergantung/Overhanged}

Sebilah balok yang ujungnya tidak tertumpu 
atau melewati tumpuan, seperti gambar 7 .

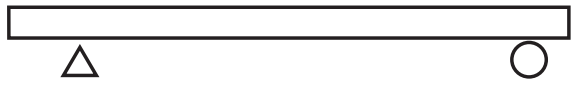

Gambar 7 : Balok Tergantung

\section{5) Balok Kontinyu.}

Sebilah balok dimana tertumpu lebih dari 2 tumpuan, seperti gambar 8 di bawah ini.

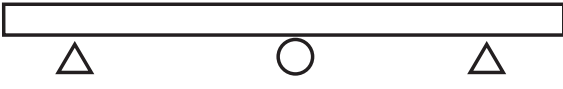

Gambar 8 : Balok Kontinyu

\section{Perbandingan Ukuran Utama Kapal}

Dalam perancangan kapal, harga perbandingan ukuran utama dan koefisien bentuk kapal sangat penting. Dalam prarancangan sebuah kapal setelah mendapatkan ukuran utama perlu dilakukan pengecekan terhadap perbandingan ukuran utama dan koefisien bentuknya sesuai daftar perbandingan kapal-kapal sejenis atau kapal pembanding.

Perbandingan ukuran utama tersebut dapat dijadikan acuan atau pedoman agar kapal yang kita rancang akan mempunyai karakteristik yang baik. Daftar perbandingan ukuran utama maupun daftar koefisien bentuk didasarkan kepada pengamatan dari kapal-kapal yang telah dirancang atau dibangun terdahulu, sehingga dapat dijadikan suatu ketetapan umum.

Perbandingan ukuran utama dalah L/B, L/H, $\mathrm{B} / \mathrm{T}$, dan $\mathrm{H} / \mathrm{T}$, harga perbandingan kapal yang berpengaruh terhadap kekuatan kapal adalah:

1. Panjang Kapal (L), untuk displasemen yang tetap, mempunyai pengaruh terhadap kecepatan kapal serta kekuatan memanjang kapal. Pertambahan panjang (L) kapal akan mengurangi tahanan badan kapal di bawah garis air saat kapal bergerak dan mengurangi kemampuan olah gerak kapal (manouvering), sebaliknya akan mengurangi kekuatan memanjang kapal karena berkurangnya modulus penampang (gading) kapal. Pengurangan panjang kapal (L) untuk displasemen tetap akan menambah lebar kapal sehingga tahanan kapan menjadi lebih besar, untuk hal tersebut perlu dijelaskan lebih lanjut pada penjelasan pada nomor di bawah ini.

2. Perbandingan $\mathrm{L} / \mathrm{H}$ yang besar akan mempunyai pengaruh terhadap berkurangnya kekuatan memanjang kapal, sebaliknya bila harga $\mathrm{L} / \mathrm{H}$ kecil menambah kekuatan memanjang kapal.

\section{Daerah Sepanjang Badan Kapal}

Tabel faktor-faktor yang mempengaruhi beban air laut pada sisi badan kapal dan geladak kapal, ditentukan koefisien sebagai berikut:

DAFTAR PERBANDINGAN UKURAN UTAMA

\begin{tabular}{|c|c|c|c|c|c|c|}
\hline NO. & $\begin{array}{c}\text { TIPE } \\
\text { KAPAL }\end{array}$ & $\begin{array}{l}\text { HARGA } \\
\text { L/B }\end{array}$ & $\begin{array}{l}\text { HARGA } \\
\text { T/B }\end{array}$ & $\begin{array}{c}\text { HARGA } \\
\mathrm{B} / \mathrm{H}\end{array}$ & $\begin{array}{c}\text { HARGA } \\
\mathrm{T} / \mathrm{H}\end{array}$ & $\begin{array}{c}\text { HARGA } \\
\mathrm{L} / \mathrm{H}\end{array}$ \\
\hline 1. & $\begin{array}{l}\text { Kapal Cepat Besar } \\
\text { Vd }=22 \text { knots }\end{array}$ & $8,50-9,90$ & $0.37-0,43$ & $1,45-1,55$ & $0,58-0,66$ & $12,80-14,90$ \\
\hline 2. & $\begin{array}{l}\text { Kapal Barang Besar } \\
\text { Vd = 15-18 knots }\end{array}$ & $8,90-9,00$ & $0,40-0,50$ & $1,50-1,70$ & $0,64-0,80$ & $13,30-15,00$ \\
\hline 3. & $\begin{array}{l}\text { Kapal Barang Besar } \\
\text { Vd }=10-15 \text { knots }\end{array}$ & $7,00-8,50$ & $0,40-0,50$ & $1,50-1,80$ & $0,66-0,82$ & $11,60-14,00$ \\
\hline 4. & Kapal Sedang & $6,00-8,00$ & $0,40-0,50$ & $1,55-2,20$ & $0,70-0,99$ & $11,00-15,40$ \\
\hline 5. & $\begin{array}{l}\text { Kapal Cepat Jarak } \\
\text { Pendek. } \\
\text { Vd }=16-23 \text { knots }\end{array}$ & $7,50-8,50$ & $0,25-0,35$ & $1,60-1,70$ & $0,41-0,58$ & $12,40-14,00$ \\
\hline 6. & Kapal Ikan & $5,00-6,00$ & $0,45-0,48$ & $1,60-1,80$ & $0,74-0,84$ & $8,50-10,00$ \\
\hline 7. & $\begin{array}{l}\text { Kapal Tunda } \\
\text { Samudra }\end{array}$ & $4,50-6,00$ & $0,37-0,47$ & $1,65-1,85$ & $0,65-0,82$ & $7,90-10,50$ \\
\hline 8. & $\begin{array}{l}\text { Kapal Tunda } \\
\text { Pelabuhan }\end{array}$ & $3,50-5,50$ & $0,37-0,46$ & $1,73-2,20$ & $0,73-0,90$ & $7,80-10,00$ \\
\hline 9. & $\begin{array}{l}\text { Kapal-kapal } \\
\text { Kecil }\end{array}$ & $6,00-8,50$ & $0,35-0,45$ & $1,50-1,70$ & $0,56-0,72$ & $9,60-13,60$ \\
\hline 10. & $\begin{array}{l}\text { Kapal-kapal Motor } \\
\text { Kecil (Layar) }\end{array}$ & $3,20-6,30$ & $0,30-0,50$ & 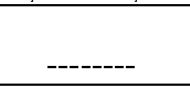 & $0,60-0,80$ & $6,00-11,00$ \\
\hline
\end{tabular}

Sumber: Teori Bangunan Kapal, I Gusti Made Santoso dkk. 


\begin{tabular}{|c|c|c|c|}
\hline \multicolumn{2}{|c|}{ Daerah } & Faktor $C_{D}$ & Faktor $\mathrm{C}_{\mathrm{F}}$ \\
\hline $\begin{array}{c}\text { Buritan } \\
\text { A }\end{array}$ & $0 \leq \frac{X}{L} \leq$ & $1,2-\frac{X}{L}$ & $1,0+-\frac{5}{C B}-\left[0,2-\frac{X}{L}\right]$ \\
\hline $\begin{array}{l}\text { Tengah } \\
\mathrm{M}\end{array}$ & $0,2 \leq \frac{X}{L} \leq 0,7$ & 1,0 & 1,0 \\
\hline $\begin{array}{l}\text { Haluan } \\
\qquad \mathrm{F}\end{array}$ & $0,7 \leq \frac{X}{L} \leq 1,0$ & $\begin{array}{l}\quad 1,0+-\frac{C}{3}\left[\frac{X}{L}-0,7\right] \\
C=0,15 \mathrm{~L}-10 \\
\text { dimana } \\
\text { Lmin }=100 \mathrm{~mm} \\
\operatorname{Lmax}=250 \mathrm{~m}\end{array}$ & $1,0+-\frac{20}{C B}\left[\frac{X}{L}-0,7\right]^{2}$ \\
\hline
\end{tabular}

Sumber : Biro klasifikasi Indonesia

\section{Faktor Bahan Baja dan Korosi}

Konstruksi kapal berbahan baja harus dapat menahan dua kondisi ekstrim dalam perhitungan kekuatan kapal yaitu kapal berada dalam satu puncak gelombang (hogging) dan kapal berada dalam dua puncak gelombang (sagging), artinya konstruksi kapal dapat menahan tegangan yang terjadi pada badan kapal akibat gelombang tersebut diatas. Menurut regulasi klasifikasi Bab 2, Bagian B. 2 tentang baja konstruksi lambung kekuatan tinggi, halaman 2-1, ditentukan dengan harga tegangan luluh dan faktor keamanan, sebagai berikut:

\begin{tabular}{cc}
\multicolumn{2}{c}{ Tabel : Faktor Bahan } \\
ReH (N/mm2) & $k$ \\
265 & 0,91 \\
315 & 0,78 \\
355 & 0,72 \\
390 & 0,66
\end{tabular}

Sumber: Biro Klasifikasi Indonesia, 2004

Sedangkan untuk korosi dari bahan bajakonstruksi kapal sesuai dengan Bab 3, Bagian K. 1, tentang marjin korosi (tK) tidak boleh kurang dari tK yang terdapat pada tabel 3.6, sebagai berikut:
Tabel: Marjin Korosi Minuman

\begin{tabular}{|l|c|}
\hline \multicolumn{1}{|c|}{ Daerah } & tk min $(\mathrm{mm})$ \\
\hline $\begin{array}{l}\text { Dalam tangki balas dimana } \\
\text { geladak cuaca menjadi atap tangki, }\end{array}$ & 2,5 \\
\hline $\begin{array}{l}\text { 1,5 m di bawah tangki 1) } \\
\text { Dalam tangki minyak muatan } \\
\text { dimana geladak cuaca menjadi } \\
\text { atapnya, 1,5 m di bawah atap } \\
\text { tangki. Bagian horizontal dalam } \\
\text { tangki minyak muatan dan tangki } \\
\text { bahan bakar. }\end{array}$ & \\
\hline $\begin{array}{l}\text { Pelat geladak di bawah rumah } \\
\text { geladak yang dipasang secara } \\
\text { elastis }\end{array}$ & 3,0 \\
\hline $\begin{array}{l}\text { 1) tK = 2,5 untuk semua konstruksi } \\
\text { di dalam tangki sayap atas kapal } \\
\text { curah. }\end{array}$ & \\
\hline $\begin{array}{l}\text { Sekat bujur terbuka terhadap } \\
\text { operasi cengkram dan diberi notasi }\end{array}$ & \\
G, maka marjin korosi tK = 2,5 \\
mm.
\end{tabular}

Sumber: Biro Klasifikasi Indonesia, 2004 
Perhitungan Beban Rancangan Menurut Biro Klasifikasi Indonesia:

Geladak Kapal Beban rancangan pada geladak cuaca (PD), Bab 4, BKI 2006

$\mathrm{PD}=\mathrm{Po}_{(10+z-T) H}^{20 T} \mathrm{CD}\{\mathrm{kN} / \mathrm{m} 2\}$

$\mathrm{CD}=1,2-{ }_{L}^{X}$ daerah $\mathrm{A}($ after peak $=$ buritan kapal $)$

sesuai tabel 4.1

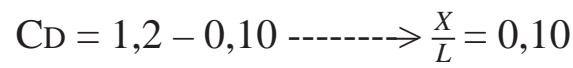

$\mathrm{CD}=1,0, \ldots \ldots \ldots \ldots . .>$ daerah $\mathrm{M}$ (middle ship $=$

tengah kapal)

$\left.\left.\mathrm{CD}=1,0+\frac{\left(10+\frac{60}{z}-7\right) H}{-7}\right), 0,7\right)$ daerah $\mathrm{F}($ fore peak $=$ haluan

kapal)

$\mathrm{C}=0,15 \mathrm{~L}-10$

$\mathrm{Po}=2,1\left(\mathrm{CB}_{\mathrm{B}}+0,7\right) \times \mathrm{C}_{\mathrm{O}} \times \mathrm{C}_{\mathrm{L}} \times \mathrm{f} \times \mathrm{C}_{\mathrm{WR}}\left(\mathrm{kN} / \mathrm{m}^{2}\right)$,

sesuai Bab 4 A. 2.2. Dimana:

$\mathrm{C}_{\mathrm{B}}=$ koefisien blok kapal

$\mathrm{C}_{\mathrm{O}}=$ koefisien gelombang

$\mathrm{C}_{\mathrm{WR}}=1,00$ untuk daerah pelayaran tak terbatas

$\mathrm{C}_{\mathrm{WR}}=0,90$ untuk daerah pelayaran $\mathrm{P}$ (samudera terbatas)

$\mathrm{C}_{\mathrm{WR}}=0,75$ untuk daerah pelayaran L (Lokal)

$\mathrm{C}_{\mathrm{WR}}=0,60$ untuk daerah pelayaran $\mathrm{T}$ (Tenang)

$\mathrm{f}=$ faktor peluang

$\mathrm{f}=1,0$ untuk panel pelat lambung luar (pelat kulit, geladak cuaca)

$\mathrm{f}=0,75$ untuk bagian penguat sekunder lambung

luar (gading-gading, balok geladak) tetapi tidak

kurang fe, sesuai Bab 5. D.1

$\mathrm{f}=0,60$ untuk penumpu dan sistem penumpu

lambung luar (gading besar, senta, sistem kisi)

tetapi tidak kurang dari $\mathrm{fQ} / 1,25$.

Rumus beban rancangan geladak

$\mathrm{PD}=\mathrm{Po} \frac{20 T}{(10+z-T) H}\left\{\mathrm{kN} / \mathrm{m}^{2}\right\}$

Dimana :

$\mathrm{Po}_{\mathrm{O}}=2,1\left(\mathrm{C}_{\mathrm{B}}+0,7\right) \times \mathrm{C}_{\mathrm{O}} \times \mathrm{C}_{\mathrm{L}} \times \mathrm{f} \times \mathrm{C}_{\mathrm{WR}}\left(\mathrm{kN} / \mathrm{m}^{2}\right)$

$\mathrm{T}=$ Sarat air kapal

$\mathrm{z}=$ jarak vertical pusat beban konstruksi di atas

garis dasar dan di bawah garis air

\section{Sisi Kapal}

Beban rancangan pada sisi kapal

Dimana :
$\mathrm{P}=\mathrm{Ps}$ atau Pe, dimana perhitungan beban rancangan untuk kulit, gading utama, senta, gading besar.

$\mathrm{PS}=10(\mathrm{~T}-\mathrm{z})+\mathrm{Po} \cdot \mathrm{CF}_{\mathrm{F}}\left(1+{ }_{T}^{Z}\right)$, untuk arah gelombang yang searah atau berlawanan dengan arah maju kapal

Daerah buritan kapal (After Peak $=\mathrm{A})$

$\mathrm{C}_{\mathrm{F}}=1,0+\underset{C B}{5}\left(0,2{ }_{L}^{X}\right)$, dimana $\frac{X}{L}=0,10$, dimana

Cb kapal

Daerah tengah kapal (Middle Ship $=\mathrm{M})$ :

$\mathrm{C}_{\mathrm{F}}=1,0$

Daerah haluan kapal (Fore Peak $=\mathrm{F})$ :

$\mathrm{C}_{\mathrm{F}}=1,0+\frac{20}{C B}\left(\frac{X}{\bar{L}^{-}}-0,7\right) 2$, dimana $\frac{X}{L}=0,93$

\section{Alas Kapal}

\section{Beban rancangan pada alas kapal}

Beban rancangan untuk penumpu pada dasar alas pada daerah buritan kapal (A), daerah tengah kapal (M), dan daerah haluan kapal (F)

$\mathrm{P}_{\mathrm{B}}=10 \mathrm{~T}+\mathrm{P}_{\mathrm{O}} \mathrm{C}_{\mathrm{F}}\left\{\mathrm{kN} / \mathrm{m}^{2}\right\}$

\section{KESIMPULAN}

Sistem konstruksi kapal harus dapat menahan terhadap gaya dari dalam kapal maupun gaya dari luar kapal.

Gaya dari dalam adalah berat kapal kosong dan bobot mati kapal, sedangkan gaya dari luar adalah gelombang air laut dan tiupan angin yang menerpa badan kapal pada saat kapal berlayar.

Faktor-faktor yang dapat mempengaruhi beban rancangan (design load) dari perhitungan konstruksi kapal antara lain adalah jenis kapal, tumpuan beban pada lambung kapal, daerah sepanjang badan kapal seperti daerah buritan kapal, daerah tengah kapal, daerah haluan kapal, daerah pelayaran, perbandingan lebar terhadap tinggi kapal, jenis baja, serta korosi baja.

\section{DAFTAR PUSTAKA}

Biro Klasifikasi Indonesia, Peraturan Klasifikasi Konstruksi Kapal Laut Baja, Peratutan Lambung, 2004.

I Gusti Made Santoso, Teori Bangunan Kapal, Departemen Pendidikan dan Kebudayaan, 1983

Lawrence H. Van Vlack, Ilmu dan Teknologi Bahan, Erlangga, Jakarta, 1995

Muhammad Mahfud, Konstruksi kapal I, Poltek Perkapalan ITS, 1994.

R.C. Hibbeler, Mekanika Teknik, Statika, 
Prenhaliindo, Jakarta, 1997

Schiffbau Technisches Handbuch, 2 Auflage, Band 1, W. Henschke, Vebverlag Technik, Berlin, 1957.

Taggart R, Ship Design Construction, SNAME, 1980

Wasono, Kamus Istilah Teknik Kapal dan Industri Kapal, IPERINDO, 2005 